\title{
The quality of dietary intake in obese pregnant women
}

\author{
M. S. Charnley ${ }^{1}$, A. Weeks ${ }^{2}$ and J. C. Abayomi ${ }^{1}$ \\ ${ }^{1}$ Faculty of Education, Community and Leisure, Liverpool John Moores University, IM Marsh Campus, Barkhill Road, \\ Liverpool L17 6BD and ${ }^{2}$ Liverpool Women's Hospital, Crown Street, Liverpool L8 7SS
}

An energy dense diet that is low in essential micronutrients can result in increased pre-gravid BMI and gestational weight gain, both of which are predictors for adverse pregnancy outcomes ${ }^{(1,2)}$. Epidemiological, observational and animal studies also provide evidence that pre-gravid BMI and gestational weight gain are implicated in the later development of metabolic diseases such as obesity, T2DM, CVD and hypertension in the offspring ${ }^{(3,4)}$. The aim of this study was to investigate the dietary intakes of obese pregnant women to determine the overall quality of diet relative to pregnancy outcomes. Participants were asked to complete three-day food diaries during each trimester of pregnancy. Data regarding food portion size was verified using a food atlas ${ }^{(5)}$ and the diaries were then analysed using Microdiet.

\begin{tabular}{|c|c|c|c|c|c|c|c|c|c|}
\hline & Energy intake $8 \cdot 1 / 8 \cdot 13^{*}$ & Total Fat g/d & SFA g/d & NSP g/d & $\begin{array}{c}\text { Calcium } \\
700 \mathrm{mg} / \mathrm{d}\end{array}$ & $\begin{array}{l}\text { Vitamin D } \\
10 \mu \mathrm{g} / \mathrm{d}^{* *}\end{array}$ & $\begin{array}{c}\text { Iron } \\
14 \cdot 8 \mathrm{mg} / \mathrm{d}\end{array}$ & $\begin{array}{c}\text { Folate } \\
300 \mu \mathrm{g} / \mathrm{d}^{* *}\end{array}$ & $\begin{array}{c}\text { Iodine } \\
140 \mu \mathrm{g} / \mathrm{d}\end{array}$ \\
\hline Visit 1 & $7 \cdot 8 \mathrm{MJ}$ & $8 \cdot 8$ & $3 \cdot 2$ & $1 \cdot 64$ & $123 \mathrm{mg}$ & $0 \cdot 37 \mu \mathrm{g}$ & $1.5 \mathrm{mg}$ & $38 \mu \mathrm{g}$ & $17 \cdot 8 \mu \mathrm{g}$ \\
\hline Visit 2 & $8 \cdot 3 \mathrm{MJ}$ & $9 \cdot 2$ & $3 \cdot 4$ & $1 \cdot 53$ & $106 \mathrm{mg}$ & $0 \cdot 27 \mu \mathrm{g}$ & $1 \cdot 17 \mathrm{mg}$ & $29 \mu \mathrm{g}$ & $15.9 \mu \mathrm{g}$ \\
\hline Visit 3 & $8 \cdot 7 \mathrm{MJ}$ & $9 \cdot 6$ & $3 \cdot 6$ & $1 \cdot 48$ & $102 \mathrm{mg}$ & $0 \cdot 27 \mu \mathrm{g}$ & $1 \cdot 34 \mathrm{mg}$ & $28 \mu \mathrm{g}$ & $16.6 \mu \mathrm{g}$ \\
\hline$\%$ change & $+11 \cdot 5$ & $+9 \cdot 1$ & $+12 \cdot 5$ & $-9 \cdot 8$ & $-17 \cdot 1$ & $-27 \cdot 0$ & $-10 \cdot 7$ & $-26 \cdot 3$ & $-6 \cdot 7$ \\
\hline
\end{tabular}

*EAR for energy in $3^{\text {rd }}$ trimester only** RNI for pregnant women ${ }^{(6)}$

Data were collected for 140 women with a BMI $\geq 35 \mathrm{~kg} / \mathrm{m}^{2}$ and a mean booking in weight of $110 \cdot 2 \mathrm{~kg}$ (SD15·7). Nutrients were measured as a proportion of $\mathrm{MJ} / \mathrm{d}$ and data shows an increase in mean total energy and fat intakes but a decrease in NSP and micronutrient intakes between visits 1 and 3 . This suggests that the quality of dietary intake deteriorated during gestation. Negative correlations between total energy intake at visit 3 and birth weight $(r=-0.285, p=0 \cdot 014)$, total fat intakes at visit $3(r=-0.272$, $p=0.020)$ were also demonstrated. Pregnancy is viewed as an ideal window of opportunity to improve eating behaviours and it may be a pertinent time to remind women that during pregnancy they are 'eating for two' when it comes to the quality of dietary intakes, as an energy dense 'empty calorie' diet with inadequate nutrient intakes may be an important determinant of future offspring obesity and disease risk.

1. Olafsdottir AS, Skuladottir GV, Thorsdottir I, Hauksson A, Steingrimsdottir L (2006) Maternal diet in early and late pregnancy in relation to weight gain. International journal of obesity 30, 492-9.

2. Sebire NJ, M Jolly, Harris JP, Wadsworth J, Joffe M, Beard RW, Regan L, Robinson S (2001) Maternal obesity and pregnancy : a study of 287213 pregnancies in London. International Journal of Obesity 25, 1175-1182.

3. Barker DJ (2007) The origins of the developmental origins theory. J Intern Med 261, 412-7.

4. Gluckman PD, Cutfield W, Hofman P, Hanson MA (2005) The fetal, neonatal, and infant environments-the long-term consequences for disease risk. Early human development 81,51-9.

5. Nelson M, Atkinson M, Meyer J (2002) A photographic atlas of food portion sizes FSA.

6. COMA (1991) Dietary Reference Values for Food, Energy \& Nutrients for the UK. HMSO: London. 